\title{
RESEARCH
}

\section{Maternal age and risk of stillbirth: a systematic review}

\author{
Ling Huang MD MSc, Reg Sauve MD MPH, Nicholas Birkett MD MSc, Dean Fergusson MHA PhD, \\ Carl van Walraven MD MSc
}

$\infty$

See related article page 183

\section{ABSTRACT}

Background: The number of women who delay childbirth to their late 30 and beyond has increased significantly over the past several decades. Studies regarding the relation between older maternal age and the risk of stillbirth have yielded inconsistent conclusions. In this systematic review we explored whether older maternal age is associated with an increased risk of stillbirth.

Methods: We searched MEDLINE, EMBASE and the Cochrane Database of Systematic Reviews for all relevant articles (original studies and systematic reviews) published up to Dec. 31, 2006. We included all cohort and case-control studies that measured the association between maternal age and risk of stillbirth. Two reviewers independently abstracted data from all included studies using a standardized data abstraction form. Methodologic and statistical heterogeneities were reviewed and tested.

Results: We identified 913 unique citations, of which 31 retrospective cohort and 6 case-control studies met our inclusion criteria. In 24 ( $77 \%$ ) of the 31 cohort studies and all 6 of the case-control studies, we found that greater maternal age was significantly associated with an increased risk of stillbirth; relative risks varied from $\mathbf{1 . 2 0}$ to 4.53 for older versus younger women. In the 14 studies that presented adjusted relative risk, we found no extensive change in the direction or magnitude of the relative risk after adjustment. We did not calculate a pooled relative risk because of the extreme methodologic heterogeneity among the individual studies.

Interpretation: Women with advanced maternal age have an increased risk of stillbirth. However, the magnitude and mechanisms of the increased risk are not clear, and prospective studies are warranted.

Une version française de ce résumé est disponible à l'adresse www.cmaj.ca/cgi/content/full/I78/2/I65/DCI

$C M A J$ 2008;178(2):165-72

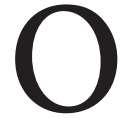
ver the past several decades, economic, technologic and social changes in the developed world have significantly increased the number of women who delay childbirth to their late 30 s and beyond. Between I980 and 1993 in the European Union, the mean maternal age at first birth rose by I. 5 years, from 27.I to 28.6 years. ${ }^{1}$ Between I99I and $200 \mathrm{I}$ in the United States, the percentage of first births for women $35-39$ years of age increased by $36 \%$ and that for women $40-44$ years of age increased by $70 \% .^{2,3}$ This huge demographic shift has become an important public health issue, since numerous studies have indicated that increased maternal age (35 years of age or older) is associated with an increased risk of maternal morbidity, obstetric interventions and adverse pregnancy outcomes. ${ }^{4-11}$

The intention to conceive and the timing of conception are complex issues influenced by many factors. Understanding the potential outcomes of pregnancy at an advanced maternal age may constitute one of these factors. Stillbirth, or late fetal death, is one of the adverse pregnancy outcomes of most concern, but studies on the relation between increased maternal age and stillbirth risk have led to inconsistent conclusions. We therefore conducted a systematic review of observational studies to explore the association between advanced maternal age and the risk of stillbirth.

\section{Methods}

\section{Literature search}

To identify relevant studies, we searched the medical literature for articles published up to Dec. 3I, 2006, using MEDLINE (from 1966), EMBASE (from I980) and the Cochrane Database of Systematic Reviews. The search terms included "maternal age," "childbearing," "fetal death," "perinatal mortality" and terms identifying observational studies and systematic reviews (for search strategies, see online Appendix I available at www.cmaj.ca/cgi/content/full/I78/2/I65/DC2). We also hand-searched the bibliographies of retrieved articles to identify additional related studies. We did not attempt to identify articles from the grey literature (unpublished studies with limited distribution, e.g., conference proceedings, theses, website archives or newsletters). No language restriction was imposed.

From the Health Surveillance and Epidemiology Division (Huang), Centre for Health Promotion, Public Health Agency of Canada, Ottawa, Ont.; the Departments of Paediatrics and of Epidemiology and Community Health Sciences (Sauve), University of Calgary, Calgary, Alta.; the Department of Epidemiology and Community Medicine (Birkett) and the Centre for Transfusion Research (Fergusson), University of Ottawa, Ottawa, Ont.; and the Clinical Epidemiology Program (Fergusson, van Walraven), Ottawa Health Research Institute, Ottawa, Ont. 


\section{Study selection}

We included all cohort studies (prospective or retrospective) and all case-control studies that examined the association between advanced maternal age and stillbirth risk. To be included in the systematic review, studies had to cite the odds ratio or relative risk of stillbirth by maternal age or had to provide sufficient data to allow us to construct contingency tables detailed enough to calculate the relative risk of stillbirth by maternal age.

\section{Data abstraction and quality assessment}

Two reviewers (L.H. and C.v.W.) independently abstracted data from all of the included studies. Abstracted data included study design; type of database used for analysis (population-based or hospital-based), if any; characteristics of the study subjects, including plurality (singletons, multiple births or both) and parity (nullipara, multipara or both); stillbirth definition in terms of gestational week and birth weight; types of stillbirths included; potential confounders or effect modifiers considered; numbers of live births and stillbirths by maternal age group; and risk ratio or odds ratio for stillbirth. We assessed the quality of each study using the Newcastle-Ottawa Scale for nonrandomized studies in meta-analyses. ${ }^{12}$ Differences in data abstraction were resolved by consensus after reference back to the original article. The interobserver agreement for data abstraction was measured using weighted kappa statistics. ${ }^{13}$

\section{Data analysis}

We recorded both the crude and (if available) adjusted risk ratio or odds ratio and $95 \%$ confidence interval (CI) for still-

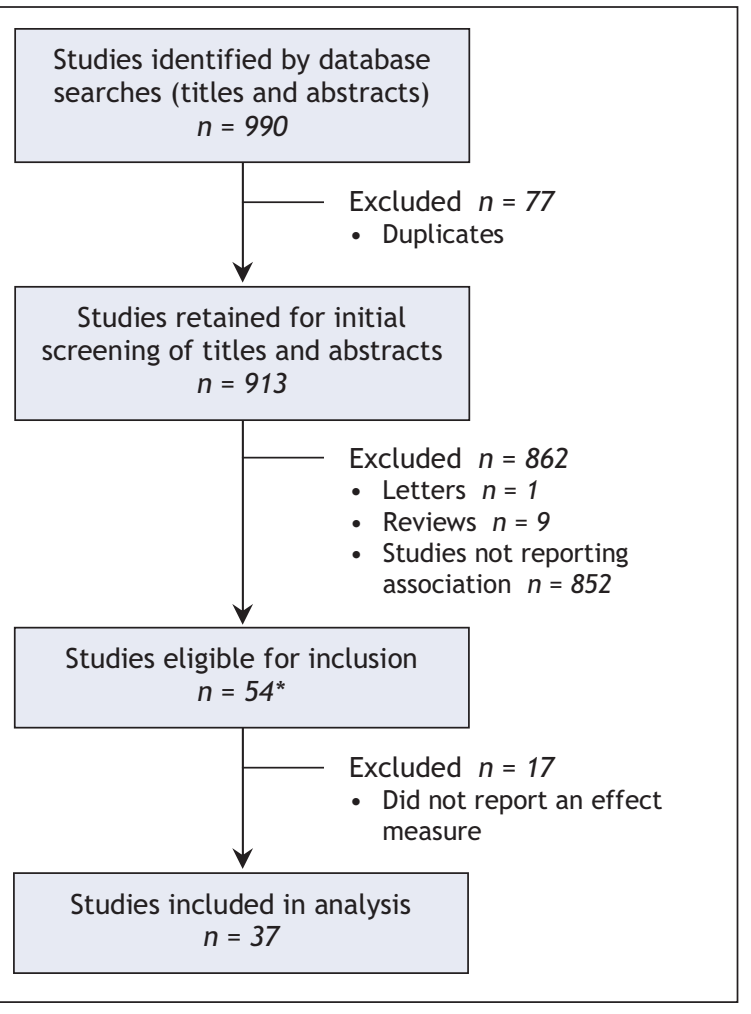

Figure 1: Selection of studies for systematic review. *Includes 3 studies identified through manual search. birth risk by maternal age for each individual study. Risk ratios and odds ratios greater than I.o indicate an increased risk of stillbrith among older women. We assessed the heterogeneity of the results of the individual studies using the Cochran Q-test for all studies, for population-based cohort studies, for hospital-based cohort studies and for casecontrol studies.

\section{Results}

Through the literature search, we initially identified 913 unique citations (Figure I). After our detailed review, 37 studies (3I retrospective cohort studies ${ }^{7,10,11,14-41}$ and 6 casecontrol studies ${ }^{42-47}$ ) met the inclusion criteria. Of the included studies, 16 were from Europe, 9 from North America, 5 from Asia, 4 from Latin America and 3 from Africa. Thirty-two of the studies were published in English, and the remaining 5 were published in French, Spanish, German or Italian. The literature search also identified 2I relevant systematic reviews. However, none of these reviews reported a systematic search for or analysis of individual studies focusing on the relation between advanced maternal age and stillbirth risk. Overall, the studies included in our review were of high quality: all studies scored 7 or higher on the Newcastle-Ottawa scale (maximum score 9). Of the 37 studies, 20 (54\%) scored 9, 5 (I4\%) scored 8, and I2 (32\%) scored 7 (Table I). The kappa score was 0.92 , which indicated very good agreement between the reviewers with regard to study quality score. ${ }^{48}$

The characteristics of the individual studies are summarized in Appendix 2 (available online at www.cmaj.ca/cgi/content |full/178/2/165/DC2). Data collection extended from 1959 to as recently as 2003. Most of the studies were very large, with a median sample size of 78453 births or women. In 17 of the studies, multiple births were included in the analysis. Studies varied with regard to criteria for defining stillbirth, and some had no specific gestational age or birth weight criteria for stillbirth. In I6 studies there was no adjustment for any other variables when the association of maternal age with stillbirth risk was measured. Studies varied extensively in their definitions of increased maternal age and in terms of the maternal age group used as the comparator. Fifteen studies excluded births among women lower than a particular age. Notably, in only 2 of the studies was maternal age entered into the regression model as a continuous variable, ${ }^{40,46}$ but these studies did not report a linearity check for the association between maternal age and stillbirth risk. It is important to take into account possible nonlinearity when a continuous exposure is included in conventional logistic regression models, since violation of the assumption of a linear logit relation between the continuous exposure and outcome can invalidate analyses.

We found statistical heterogeneity for all included studies, for the population-based cohort studies and for the hospital-based cohort studies $(p<0.00$ I for the 3 tests of heterogeneity). The results of the case-control studies were homogeneous $(p=0.40)$. Because of the statistical and important clinical and methodological heterogeneities, we did not perform meta-analytic combination of the results of these studies. 
Among the 3I retrospective cohort studies, 24 (77\%) had a statistically significant association between increased maternal age and stillbirth (Figure 2). In addition, for all I5 population-based studies, there was a significant association between increased maternal age and stillbirth risk. The reported crude relative risk of stillbirth varied from I.20 to 4.53 for older versus younger women. The most commonly used definition of advanced maternal age in these studies was 35 years or more for older women, with age less than 35 years or 20-34 years used as the reference group (these 2 definitions were used in Io of the 24 studies). The authors of these io studies reported a stillbirth risk among older women that was I. 26 to I.92 times higher than the risk among women less than 35 years of age. In 7 of the 3 I studies, there was no statistically significant relation between older maternal age and stillbirth risk. All of these 7 studies were based on hospital-level databases (Figure 2). In all 6 casecontrol studies, there was a significant relation between advanced maternal age and stillbirth risk; the crude odds ratios were similar to those reported for the cohort studies (Figure 2).

In 2 I $(57 \%)$ of the studies (I5 retrospective cohort studies and all 6 case-control studies), the researchers controlled for potential confounders when measuring the association between maternal age and stillbirth risk. Both crude and adjusted risk ratios or odds ratios were reported for I4 of these 2I studies (Figure 3). Different confounders were adjusted for in each study, most frequently parity and smoking, followed by education, race, chronic medical problems, prenatal care and body mass index. After adjustment for confounders, the risk ratios or odds ratios did not change extensively in either magnitude or direction. The one exception was the study by Sheiner and colleagues, ${ }^{38}$ in which the crude relative risk of $\mathrm{I} .48$ (95\% CI $0.74^{-2.96}$ ) among women more than 35 years of age increased to 2.I0 (95\% CI I.IO-3.80) after adjustment.

\section{Interpretation}

The number of women who are experiencing childbirth at an older age is increasing dramatically. We identified 37

studies $(n=31)$

Astolfi et $\mathrm{al}^{14}$

Astolfi et $\mathrm{al}^{15}$

Bianco et $\mathrm{al}^{16}$

Canterino et $\mathrm{al}^{17}$

Donoso et $\mathrm{al}^{19}$

Feldman ${ }^{20}$

Feresu et $\mathrm{al}^{21}$

Fretts et $\mathrm{al}^{10}$

Fretts et $\mathrm{al}^{22}$

Gadow et $\mathrm{al}^{23}$

Glinianaia et $\mathrm{al}^{24}$

Haglund et $\mathrm{al}^{25}$

Heimann et $\mathrm{al}^{26}$

Jacobsson et $\mathrm{al}^{27}$

Jolly et $\mathrm{al}^{7}$

Khandait et $\mathrm{al}^{28}$

Kristensen et $\mathrm{al}^{29}$

Lammer et $\mathrm{al}^{30}$

Naeye $^{31}$

Pugliese et $\mathrm{al}^{33}$

Raymond et $\mathrm{al}^{35}$

Roman et $\mathrm{al}^{36}$

Seoud et $\mathrm{al}^{37}$

Sheiner et $\mathrm{al}^{38}$

Tough et $\mathrm{al}^{39}$

Viegas et $\mathrm{al}^{40}$

Ziadeh $^{41}$

Ferraz et $\mathrm{al}^{42}$

Little et $\mathrm{al}^{43}$

Meda et $\mathrm{al}^{44}$

Petridou et $\mathrm{al}^{45}$

Smeeton et $\mathrm{al}^{46}$ studies that examined the association between increased maternal age and stillbirth, more than $80 \%$ of which demonstrated a statistically significant increase in the risk
Table 1: Quality assessment* of 37 individual studies of the association between advanced maternal age and stillbirth risk that were included in the systematic review

\begin{tabular}{|c|c|c|c|c|}
\hline Study & Selection & Comparability & $\begin{array}{l}\text { Outcome } \\
\text { or exposure }\end{array}$ & $\begin{array}{l}\text { Total } \\
\text { score }\end{array}$ \\
\hline
\end{tabular}

Retrospective cohort

Cnattingius et $\mathrm{al}^{11}$

Conde-Agudelo et $\mathrm{al}^{18}$

Nybo Anderson et $\mathrm{al}^{32}$

Rasmussen et $\mathrm{al}^{34}$

Case-control studies $(n=6)$

Stephansson et $\mathrm{al}^{47}$

\begin{tabular}{|c|c|c|c|}
\hline$\star \star \star \star$ & $\star \star$ & $\star \star \star$ & 9 \\
\hline$\star \star \star \star$ & $\star \star$ & $\star \star \star$ & 9 \\
\hline$\star \star \star \star \star$ & $\star \star$ & $\star \star \star$ & 9 \\
\hline$\star \star \star \star$ & $\star \star$ & $\star \star \star$ & 9 \\
\hline$\star \star \star \star$ & $\star \star$ & $\star \star \star$ & 9 \\
\hline$\star \star \star \star \star$ & $\star \star$ & $\star \star \star$ & 9 \\
\hline$\star \star \star \star \star$ & & $\star \star \star$ & 7 \\
\hline$\star \star \star \star \star$ & $\star$ & $\star \star \star$ & 8 \\
\hline$\star \star \star \star$ & & $\star \star \star$ & 7 \\
\hline$\star \star \star \star \star$ & $\star \star$ & $\star \star \star$ & 9 \\
\hline$\star \star \star \star$ & & $\star \star \star$ & 7 \\
\hline$\star \star \star \star$ & & $\star \star \star$ & 7 \\
\hline$\star \star \star \star \star$ & $\star$ & $\star \star \star$ & 8 \\
\hline$\star \star \star \star$ & $\star \star$ & $\star \star \star$ & 9 \\
\hline$\star \star \star \star \star$ & & $\star \star \star$ & 7 \\
\hline$\star \star \star \star$ & $\star \star$ & $\star \star \star$ & 9 \\
\hline$\star \star \star \star$ & $\star \star$ & $\star \star \star$ & 9 \\
\hline$\star \star \star \star \star$ & & $\star \star \star$ & 7 \\
\hline$\star \star \star \star$ & $\star \star$ & $\star \star \star$ & 9 \\
\hline$\star \star \star \star \star$ & & $\star \star \star$ & 7 \\
\hline$\star \star \star \star$ & & $\star \star \star$ & 7 \\
\hline$\star \star \star \star \star$ & & $\star \star \star$ & 7 \\
\hline$\star \star \star \star$ & & $\star \star \star$ & 7 \\
\hline$\star \star \star \star$ & $\star$ & $\star \star \star$ & 8 \\
\hline$\star \star \star \star \star$ & $\star \star$ & $\star \star \star$ & 9 \\
\hline$\star \star \star \star$ & $\star$ & $\star \star \star$ & 8 \\
\hline$\star \star \star \star \star$ & $\star$ & $\star \star \star$ & 8 \\
\hline$\star \star \star \star$ & $\star \star$ & $\star \star \star$ & 9 \\
\hline$\star \star \star \star$ & & $\star \star \star$ & 7 \\
\hline$\star \star \star \star$ & $\star \star$ & $\star \star \star$ & 9 \\
\hline$\star \star \star \star$ & & $\star \star \star$ & 7 \\
\hline$\star \star \star \star$ & $\star \star$ & $\star \star \star$ & 9 \\
\hline$\star \star \star \star$ & $\star \star$ & $\star \star \star$ & 9 \\
\hline$\star \star \star \star$ & $\star \star$ & $\star \star \star$ & 9 \\
\hline$\star \star \star \star$ & $\star \star$ & $\star \star \star$ & 9 \\
\hline$\star \star \star \star \star$ & $\star \star$ & $\star \star \star$ & 9 \\
\hline$\star \star \star \star$ & $\star \star$ & $\star \star \star$ & 9 \\
\hline
\end{tabular}

According to the Newcastle-Ottawa Scale for nonrandomized studies in meta-analyses. ${ }^{12}$ Maximum score for selection $=4$ stars, maximum score for comparability $=2$ stars, maximum score for outcome (for retrospective cohort studies) or exposure (for case-control studies) $=3$ stars, maximum total score $=9$. 


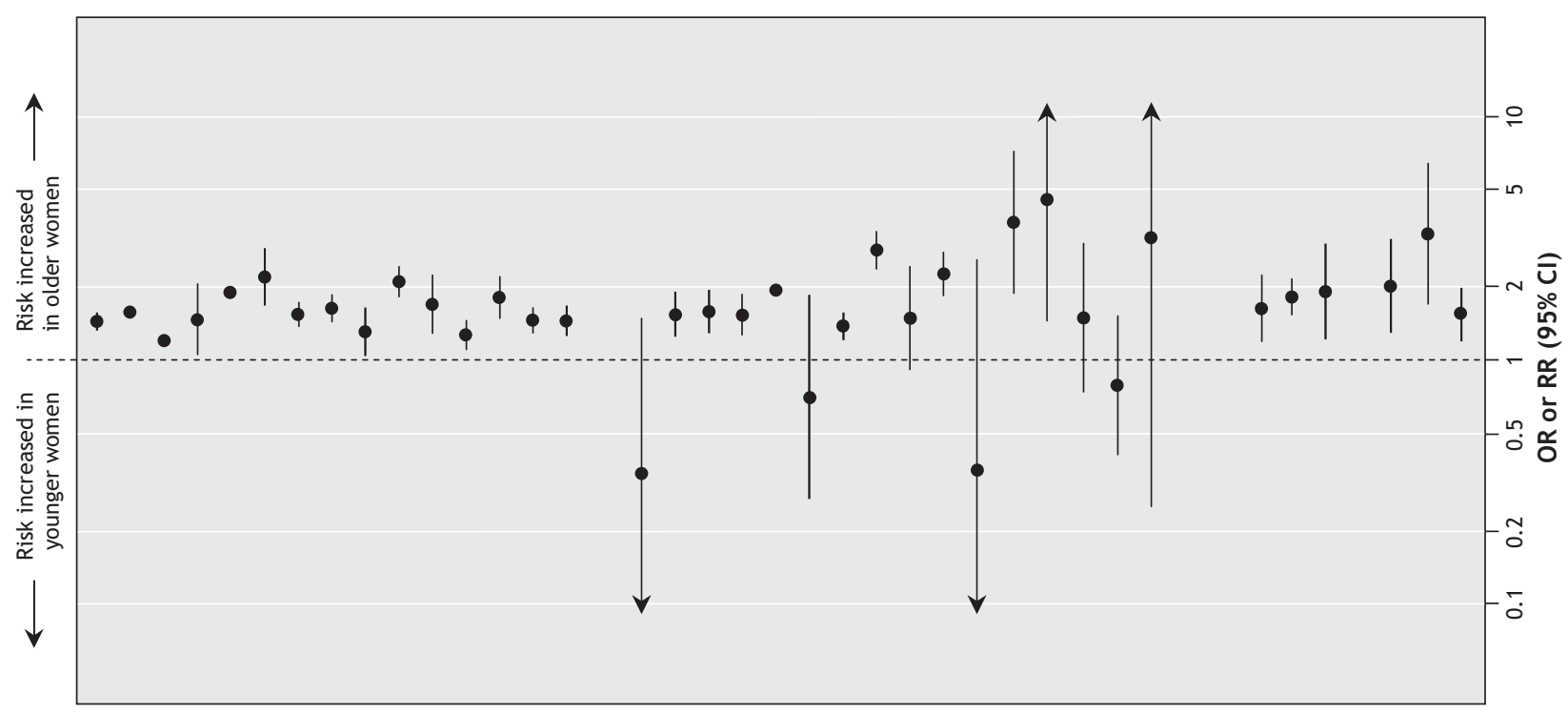

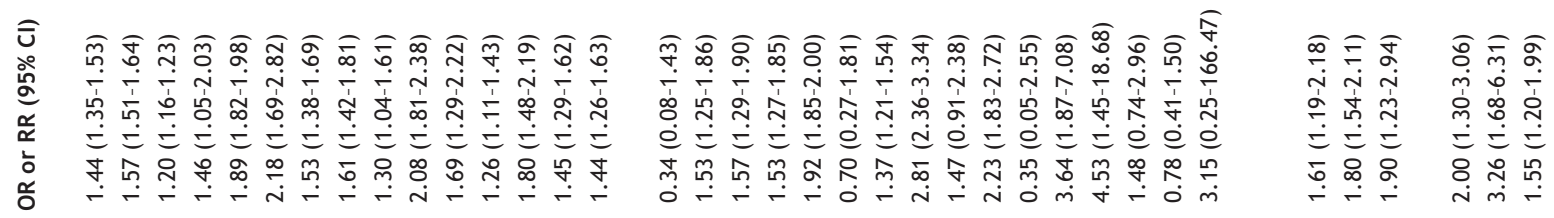

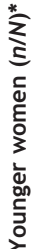

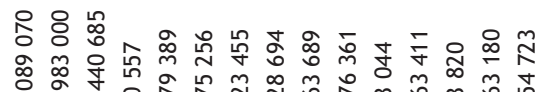

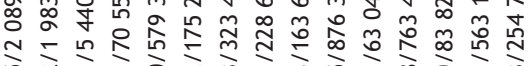

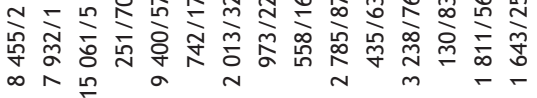

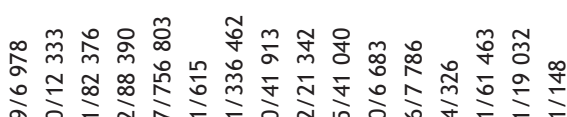

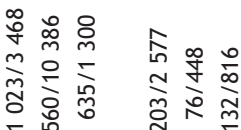

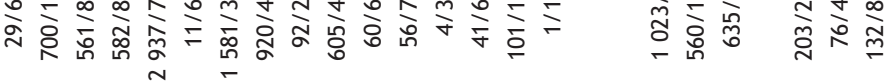

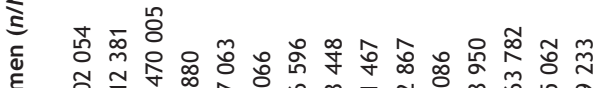

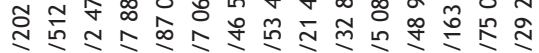

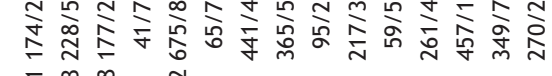

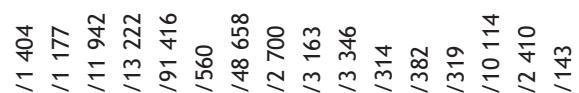

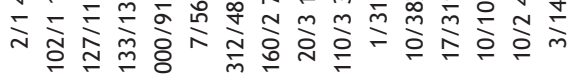

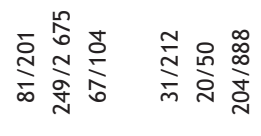

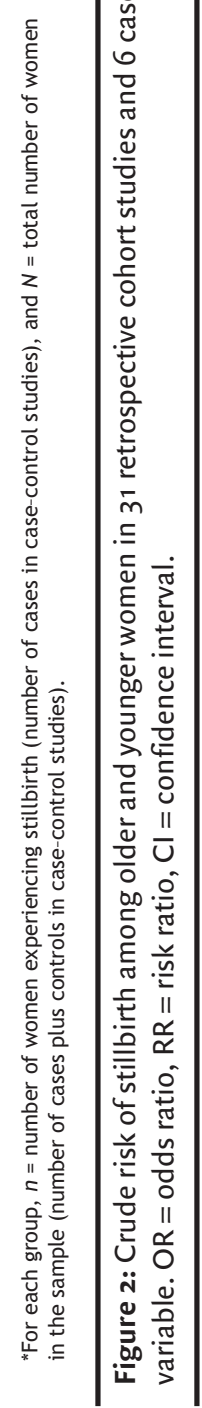




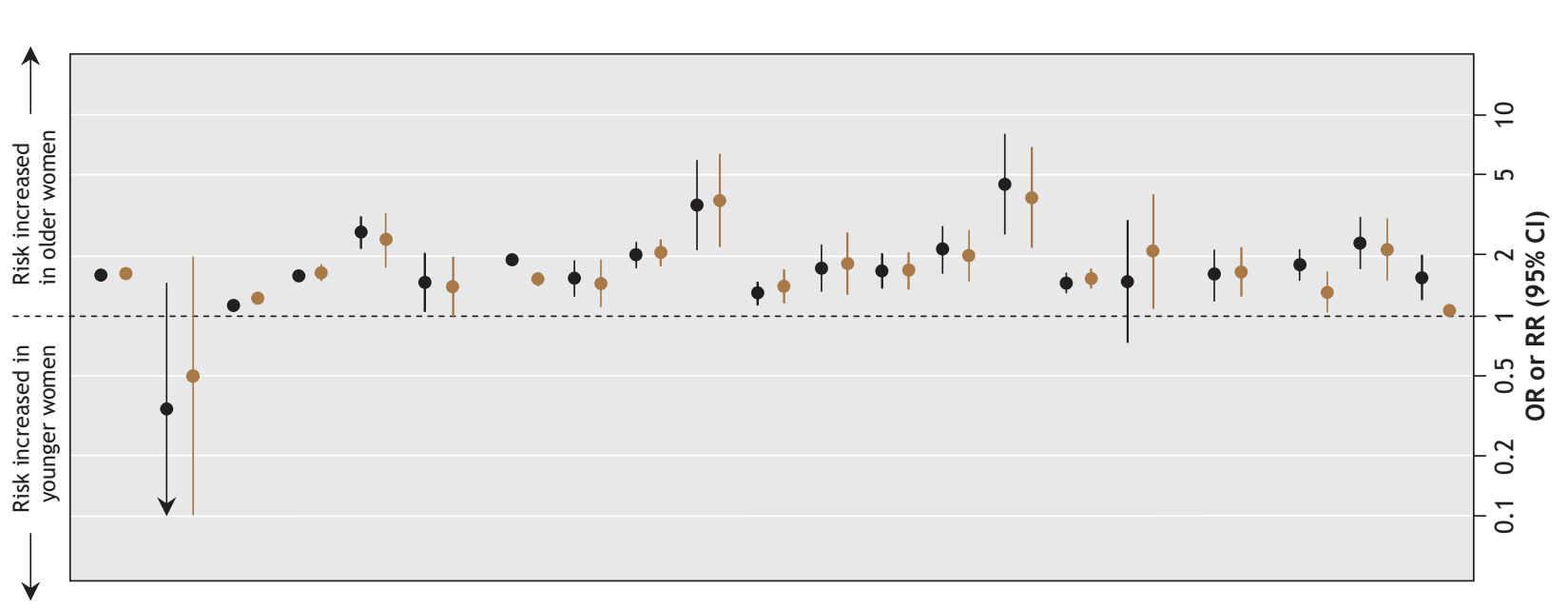

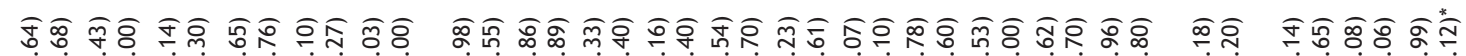
-

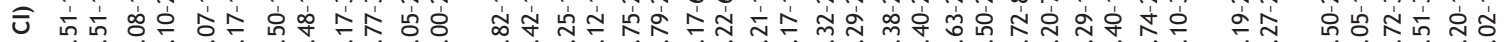
每

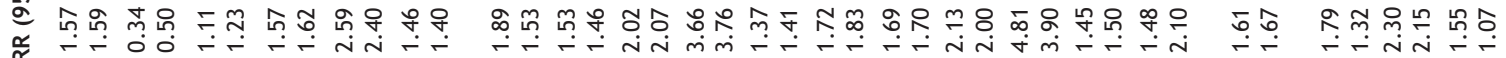

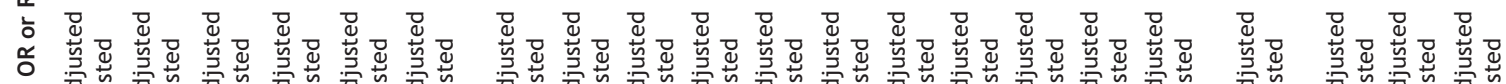

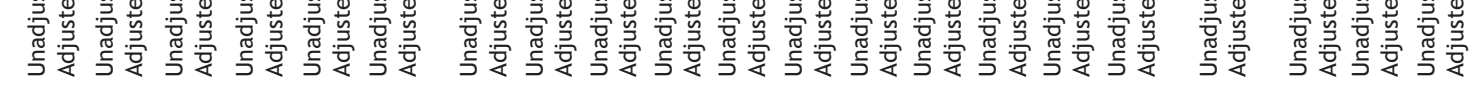

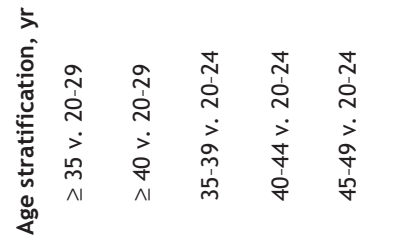

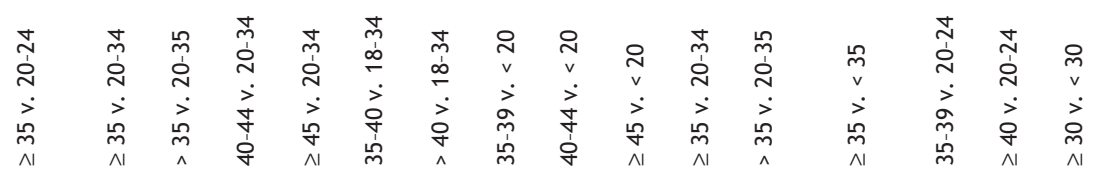

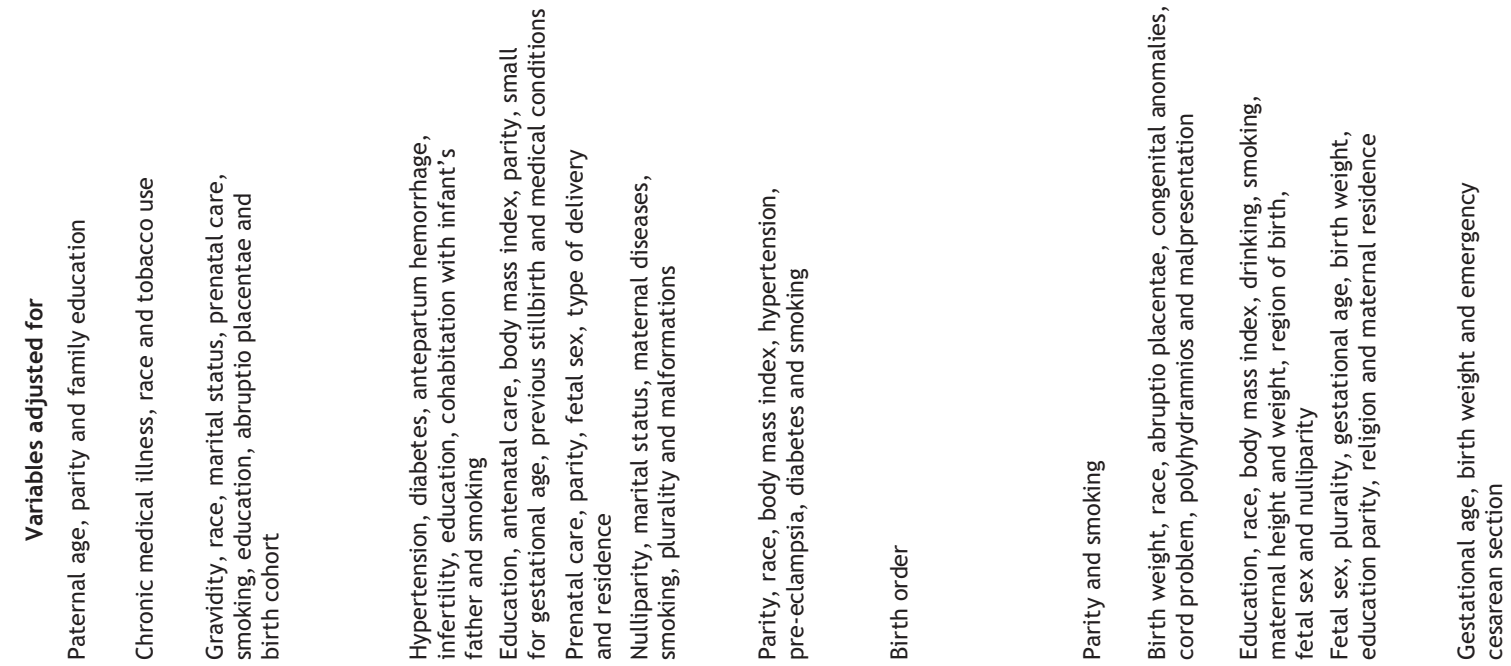

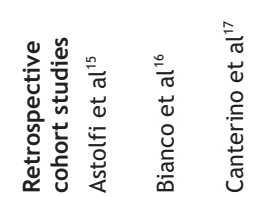

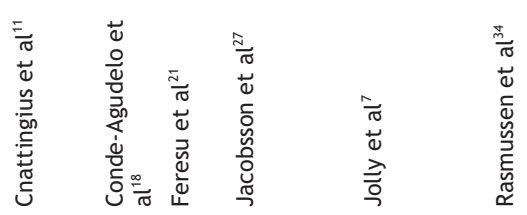

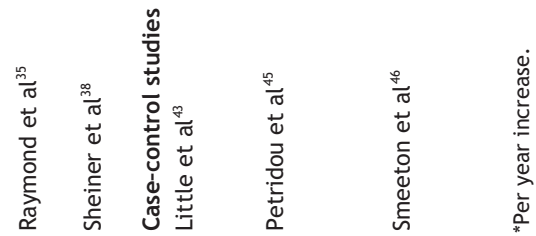


of stillbirth among women of advanced maternal age. However, the absolute increase in risk was relatively small in studies from developed countries, with crude odds ratios varying from I.2O to 2.23 on top of baseline stillbirth rates varying from 1.55 to 17.89 per Iooo total births. Fourteen studies adjusted this association for potential confounders, and 8 of them found less than a 10\% difference between crude and adjusted relative risks or odds ratios. This result suggests that the association between increased maternal age and stillbirth risk is probably independent of many other known factors that could increase with age.

The biological mechanism of the increase in stillbirth risk with advanced maternal age is uncertain. A direct effect of maternal aging may exist. This would probably be related to low uteroplacental perfusion caused by poor uterine vasculature in older women. ${ }^{31}$ The increased risk could also be attributed to the association between older age and certain risk factors for stillbirths, such as chronic diseases and medical or obstetric complications. Older women have a higher risk of experiencing pregnancy-induced hypertension or gestational diabetes. ${ }^{4}$ Between $50 \%$ and $70 \%$ of mothers of stillborn infants had medical or pregnancy complications during their pregnancies. ${ }^{49}$ The relative contributions of advanced maternal age and chronic conditions that may influence pregnancy outcomes remain to be fully elucidated. Additional studies are required to determine the mechanism by which advanced maternal age increases stillbirth risk.

Maternal age and parity are 2 closely related demographic factors. They are commonly included in obstetric care records because of their influences on pregnancy complications and outcomes. In clinical practice, both older nulliparous and younger multiparous women are considered to be at increased risk of adverse pregnancy outcomes. Studies have demonstrated that the association of maternal age with outcomes, including placenta previa and abruptio placentae $e^{50}$ and neonatal mortality, ${ }^{51}$ varies significantly by parity. However, few researchers have used multivariate regression analysis to address the interaction between parity and maternal age in terms of its effect on the risk of stillbirths. For example, only $3(8 \%)$ of the 37 individual studies in our review included a test for interaction between parity and maternal age. Further study is required to explore this interaction in more detail.

We did not perform a meta-analysis to determine an overall effect measure because of extensive heterogeneity in study design, measurement and even definition of stillbirth across the studies. There were several other notable variations among the studies. First, the definition of "increased maternal age" was variable (see Appendix 2, available online at www.cmaj.ca/cgi/content/full/178/2/165/DC2). This variation probably reflects the clinical uncertainty about the maternal age at which stillbirth risk increases. In 1958 the International Federation of Gynecology and Obstetrics defined pregnant women 35 years or older as "elderly primigravidae." ${ }^{22}$ In obstetric practice, pregnant women older than 35 years have been regarded as being at higher risk and are considered for routine genetic screening. However, the 35-year threshold is not applicable for healthy women who do not engage in risky behaviours such as smoking, because neona- tal outcomes in such women do not change up to the age of 40 years. ${ }^{53}$ Other researchers have even suggested that, in the absence of pre-existing medical disorders, pregnancy at 45 to 50 years of age is safe. ${ }^{8}$ Because it is difficult to assign a risk cut point to a continuous variable such as age, we believe that future studies should model age as a continuous variable when its association with stillbirth risk is being considered.

The inclusion or exclusion of multiple births was a second major source of heterogeneity among the studies, with some researchers including all deliveries and others excluding women with multiple births. Complications such as low birth weight, preterm labour and stillbirth are more likely with multiple births. ${ }^{54-57}$ Older women are I.5 to 2 times more likely than younger women to have a multiple birth, ${ }^{40,58-60}$ at least in part because of their greater use of assisted reproductive technology. Therefore, we recommend that future studies examining the association between increased maternal age and stillbirth risk exclude multiple births or carefully consider their effect.

Study setting was a third major source of heterogeneity. Of the 16 hospital-based cohort studies, 7 had no statistically significant increase in the risk of stillbirth with older maternal age. Most of these 7 studies were performed in academic hospitals or medical centres. Older women with high socioeconomic status may seek obstetric care in academic hospitals, especially when delivering their first baby. At the same time, many of these hospitals are located in impoverished neighbourhoods, where young women with low socioeconomic status typically receive their routine obstetric care. An increased risk of adverse obstetric outcomes for these women may obscure the association between advanced maternal age and stillbirth risk.

The association between increased maternal age and stillbirth risk was essentially similar across the studies, despite the extensive methodologic heterogeneity. In particular, population-based studies with large sample sizes, which accounted for almost half of the studies included in our review, had consistent results regarding this association. Also, adjustment for a wide variety of potential confounders had little effect on the association between maternal age and stillbirth (Figure 3). We believe that these observations suggest a stable and valid association between increased maternal age and stillbirth risk.

Women should understand that the risks associated with pregnancy increase as they get older. In this systematic review, we have demonstrated that risk of stillbirth is one of the risks that increases with advanced maternal age. However, since the absolute stillbirth rate among older women is less than Io per Iooo births in most industrialized countries, a live birth can be expected in most cases if appropriate medical care is provided. Thus, increased maternal age should not be considered an absolute barrier to the decision to have a child, at least in terms of the risk of stillbirth.

\section{Limitations}

The limitations of this systematic review stem primarily from the studies themselves. First, we did not perform a metaanalysis or meta-regression because of the extreme method- 
ologic heterogeneity across the studies. Second, few of the included studies reported a separate analysis for antepartum stillbirths (which occur before labour) and intrapartum stillbirths (which occur during labour). Given that these 2 types of stillbirth have widely different etiologic determinants, merging them might cloud studies of risk factors. Third, because information on important factors such as medical conditions, pregnancy complications, lifestyle factors and socioeconomic status are not commonly collected in administrative databases, many studies could not adjust for these factors when associating maternal age and stillbirth risk, which might weaken the internal validity of the included studies. However, investigators should be cautious when controlling for factors such as medical conditions or low birth weight in examining the relation between prenatal exposure and perinatal outcome, since these factors might be part of a causal pathway between the exposure and the outcome. In a recent study, Hernandez-Diaz and associates ${ }^{61}$ concluded that adjusting for birth weight is generally inappropriate when measuring the overall effect of maternal smoking on infant mortality; this conclusion arose through a paradoxical finding of the birth-weight effect, whereby small babies in high-risk populations usually have lower risk than small babies in low-risk populations.

\section{Implications}

In this systematic review, we have demonstrated that women with advanced maternal age have a significantly increased risk of stillbirth. We could not determine a pooled estimate of the magnitude of this risk because of heterogeneity in terms of the subjects included in the individual studies, the definitions of stillbirth, the cutoff point for older maternal age and the confounders that were adjusted for across the included studies. More studies with homogeneous design are needed to further evaluate the strength of the association between advanced maternal age and increased risk of stillbirth. Future studies should adopt the definition of stillbirth recommended by the World Health Organization ${ }^{62}$ to make comparisons between studies both feasible and accurate. Since the pathways through which older age influences the risk of stillbirth are still unclear, future studies should examine the mechanisms by which advanced maternal age leads to increased risk of stillbirth.

This article has been peer reviewed.

Competing interests: None declared.

Contributors: All of the authors contributed to conceiving the study, writing and reviewing the paper, and approving the final version for publication.

Acknowledgements: We thank Connie Barrowclough for her assistance with the literature searches; Ernesto Delgado, Susie Dzakpasu and Jocelyn Rouleau for their help with translation of the non-English papers; and Steve Doucette for his help with the homogeneity tests and preparation of the figures.

\section{REFERENCES}

I. Breart G. Delayed childbearing. Eur J Obstet Gynecol Reprod Biol 1997;75:71-3.

2. Cnattingius S, Stephansson O. The epidemiology of stillbirth. Semin Perinatol $2002 ; 26: 25-30$.
3. Heffner LJ. Advanced maternal age - How old is too old? N Engl J Med 2004;35I: I927-9

4. Joseph KS, Allen A, Dodds L, et al. The perinatal effects of delayed childbearing Obstet Gynecol 2005;105:I410-8.

5. Cleary-Goldman J, Malone FD, Vidaver J, et al. Impact of maternal age on obstetric outcome. Obstet Gynecol 2005;105:983-90.

6. Saftlas AF, Olson DR, Franks AL, et al. Epidemiology of preeclampsia and eclampsia in the United States, 1979-1986. Am J Obstet Gynecol 1990;163:460-5.

7. Jolly M, Sebire N, Harris J, et al. The risks associated with pregnancy in women aged 35 years or older. Hum Reprod 2000;15:2433-7.

8. Dildy GA, Jackson GM, Fowers GK, et al. Very advanced maternal age: pregnancy after age 45. Am J Obstet Gynecol I996;175:668-74.

9. Conde-Agudelo A, Belizan JM, Diaz-Rossello JL. Epidemiology of fetal death in Latin America. Acta Obstet Gynecol Scand 2000;79:37I-8.

Io. Fretts RC, Schmittdiel J, Mclean FH, et al. Increased maternal age and the risk of fetal death. NEngl J Med r995;333:953-7.

II. Cnattingius S, Forman MR, Berendes HW, et al. Delayed childbearing and risk of adverse perinatal outcome: a population-based study. JAMA I992;268:886-9o.

I2. Wells GA, Shea B, O'Connell D, et al. The Newcastle-Ottawa Scale (NOS) for assessing the quality of nonrandomised studies in meta-analyses. Ottawa: Ottawa Health Research Institute. Available: www.ohri.ca/programs/clinical_epidemiology/oxford.htm (accessed 2007 Nov 2).

13. Fleiss JL, Levin BA, Paik MC. Statistical methods for rates and proportions. 3rd ed. Hoboken (NJ): Wiley; 2003. p. 598-6ro.

I4. Astolfi P, Zonta LA. Delayed maternity and risk at delivery. Paediatr Perinat Epidemiol 2002;16:67-72.

I5. Astolfi P, De Pasquale A, Zonta LA. Late childbearing and its impact on adverse pregnancy outcome: stillbirth, preterm delivery and low birth weight. Rev Epidemiol Sante Publique 2005;53:S97-I05

I6. Bianco A, Stone J, Lynch L, et al. Pregnancy outcome at age 40 and older. Obstet Gynecol I996;87:917-22.

17. Canterino JC, Ananth CV, Smulian J, et al. Maternal age and risk of fetal death in singleton gestations: USA, I995-2000. JMatern Fetal Neonatal Med 2004;I5:I93-7.

I8. Conde-Agudelo A, Belizán JM, Diaz-Rossello JL. Epidemiology of fetal death in Latin America. Acta Obstet Gynecol Scand 2000;79:37I-8.

I9. Donoso E, Villarroel L. [Reproductive risk of women over 40 years old]. Rev Med Chil 2003;I31:55-9. Spanish.

20. Feldman GB. Prospective risk of stillbirth. Obstet Gynecol I992;79:547-53

2I. Feresu SA, Harlow SD, Welch K, et al. Incidence of stillbirth and perinatal mortality and their associated factors among women delivering at Harare Maternity Hospital, Zimbabwe: a cross-sectional retrospective analysis. BMC Pregnancy Childbirth 2005;5:9.

22. Fretts RC, Usher RH. Causes of fetal death in women of advanced maternal age. Obstet Gynecol I997;89:40-5.

23. Gadow EC, Castilla EE, Lopez Camelo J, et al. Stillbirth rate and associated risk factors among 869750 Latin American hospital births i982-1986. Int J Gynaecol Obstet I99I;35:209-I4.

24. Glinianaia SV, Rankin J, Bell R, et al. Temporal changes in the distribution of population risk factors attenuate the reduction in perinatal mortality. J Clin Epidemiol 2005;58:1299-307.

25. Haglund B, Cnattingius S, Nordstrom ML. Social differences in late fetal death and infant mortality in Sweden 1985-86. Paediatr Perinat Epidemiol I993;7:33-44.

26. Heimann F, Messerer D, Baltzer J. [Pregnancy, labor and fetal outcome in females over 40 years of age]. Geburtshilfe Frauenheilkd ig93;53:4II-5. German.

27. Jacobsson B, Ladfors L, Milsom I. Advanced maternal age and adverse perinatal outcome. Obstet Gynecol 2004;104:727-33

28. Khandait DW, Ambadekar NN, Zodpey SP, et al. Maternal age as a risk factor for stillbirth. Indian J Public Health 2000;44:28-30.

29. Kristensen J, Vestergaard M, Wisborg K, et al. Pre-pregnancy weight and the risk of stillbirth and neonatal death. BJOG 2005;112:403-8.

30. Lammer EJ, Brown LE, Anderka MT, et al. Classification and analysis of fetal deaths in Massachusetts. JAMA I989;261:1757-62.

3I. Naeye RL. Maternal age, obstetric complications, and the outcome of pregnancy. Obstet Gynecol ig83;61:210-6.

32. Nybo Andersen AM, Wohlfahrt J, Christens P, et al. Maternal age and fetal loss: population based register linkage study. BMJ 2000;320:I708-I2.

33. Pugliese A, Vicedomini D, Arsieri R. [Perinatal outcomes of newborn infants of mothers over 40 years old. A case-control study]. Minerva Ginecol 1997;49:8I-4. Italian.

34. Rasmussen S, Albrechtsen S, Irgens LM, et al. Risk factors for unexplained antepartum fetal death in Norway I967-1998. Early Hum Dev 2003;71:39-52.

35. Raymond EG, Cnattingius S, Kiely JL. Effects of maternal age, parity, and smoking on the risk of stillbirth. BrJObstet Gynaecol I994;IOI:30I-6.

36. Roman H, Robillard PY, Julien C, et al. [Pregnancy beyond age 40 in 382 women: a retrospective study in Reunion Island]. J Gynecol Obstet Biol Reprod (Paris) 2004; 33:615-22. French.

37. Seoud MA, Nassar AH, Usta IM, et al. Impact of advanced maternal age on pregnancy outcome. Am J Perinatol 2002;19:I-8

38. Sheiner E, Hallak M, Shoham-Vardi I, et al. Determining risk factors for intrapartum fetal death. J Reprod Med 2000;45:4I9-24.

39. Tough SC, Newburn-Cook C, Johnston DW, et al. Delayed childbearing and its impact on population rate changes in lower birth weight, multiple birth, and preterm delivery. Pediatrics 2002;109:399-403.

40. Viegas OA, Leong WP, Ahmed S, et al. Obstetrical outcome with increasing maternal age. J Biosoc Sci 1994;26:261-7. 
4I. Ziadeh SM. Maternal and perinatal outcome in nulliparous women aged 35 and older. Gynecol Obstet Invest 2002;54:6-10.

42. Ferraz EM, Gray RH. A case-control study of stillbirth in northeast Brazil. Int J Gynaecol Obstet I991;34:13-9.

43. Little RE, Weinberg CR. Risk factors for antepartum and intrapartum stillbirth. Am J Epidemiol I993;137:1177-89.

44. Meda N, Traore GS, Meda HA, et al. La mortinatalité au Burkina Faso : facteurs de risque en milieu urbain de Bobo-Dioulasso. Ann Soc Belg Med Trop I991;71:307-I6.

45. Petridou E, Kotsifakis G, Revinthi K, et al. Determinants of stillbirth mortality in Greece. Soz Praventivmed i $996 ; 41: 70-8$.

46. Smeeton NC, Rona RJ, Dobson P, et al. Assessing the determinants of stillbirths and early neonatal deaths using routinely collected data in an inner city area. BMC Med 2004;2:27.

47. Stephansson O, Dickman PW, Johansson AL, et al. The influence of socioeconomic status on stillbirth risk in Sweden. Int J Epidemiol 200I;30:1296-30I.

48. Altman DG. Practical statistics for medical research. London (UK): Chapman and Hall; r99I. p. 404.

49. Goldenberg RL, Kirby R, Culhane JF. Stillbirth: a review. J Matern Fetal Neonatal Med 2004;16:79-94.

50. Ananth CV, Wilcox AJ, Savitz DA, et al. Effect of maternal age and parity on the risk of uteroplacental bleeding disorders in pregnancy. Obstet Gynecol I996;88:5II-6.

5I. Kiely JL, Paneth N, Susser M. An assessment of the effects of maternal age and parity in different components of perinatal mortality. Am J Epidemiol I986;123:444-54

52. Ataullah I, Freeman-Wang T. The older obstetric patient. Curr Obstet Gynecol 2005;II5:46-53

53. Berkowitz GS, Skovron ML, Lapinski RH, et al. Delayed childbearing and the outcome of pregnancy. N EngI J Med I990;322:659-64.

54. Salihu HM, Shumpert MN, Slay M, et al. Childbearing beyond maternal age 50 and fetal outcomes in the United States. Obstet Gynecol 2003;I02:I006-I4.

55. Cassell KA, O'Connell CM, Baskett TF. The origins and outcomes of triplet and quadruplet pregnancies in Nova Scotia: I980 to 200I. Am J Perinatol 2004;21:439-45

56. Ventura SJ, Martin JA, Curtin SC, et al. Births: final data for 1999. Natl Vital Stat Rep 200I;49(I):I-IOo.

57. Gardner MO, Goldenberg RL, Cliver SP, et al. The origin and outcome of preterm twin pregnancies. Obstet Gynecol I995;85:553-7.

58. Russell RB, Petrini JR, Damus K, et al. The changing epidemiology of multiple births in the United States. Obstet Gynecol 2003;I0I:I29-35.

59. Zhang J, Meikle S, Grainger DA, et al. Multifetal pregnancy in older women and perinatal outcomes. Fertil Steril 2002;78:562-8.

6o. Hur YM, Kwon JS. Changes in twinning rates in South Korea: I98I-2002. Twin Res Hum Genet 2005;8:76-9.

6r. Hernandez-Diaz S, Schisterman EF, Hernan MA. The birth weight "paradox" uncovered? Am J Epidemiol 2006;164:1115-20.

62. International statistical classification of diseases and related health problems. Ioth rev, vol 2. Geneva: World Health Organization; 1993. p. I29-33.

Correspondence to: Dr. Carl van Walraven, Clinical Epidemiology Program, Ottawa Health Research Institute, Rm. C405, Ottawa Hospital, Civic Campus, I053 Carling Ave., Ottawa ON KIY 4Eg; fax6I376I-5492; carlv@ohri.ca

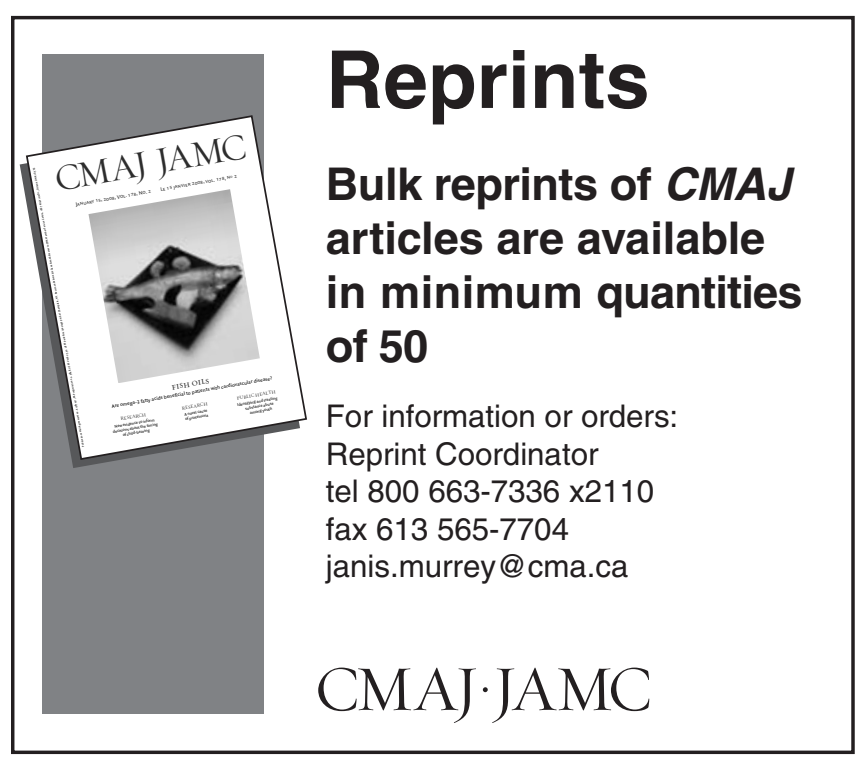

